\title{
Cardiac magnetic resonance imaging in pediatric patients $\leq 18$ years with suspected arrhythmogenic right ventricular cardiomyopathy (ARVC): a correlation to genetics
}

\author{
Wieland Staab ${ }^{2,4}$, Peter Lauerer ${ }^{1}$, Martin Fasshauer ${ }^{2,4}$, Ulrich J Krause ${ }^{1}$, Jan M Sohns ${ }^{2,4}$, Andreas Schuster ${ }^{3,4}$, \\ Christina Unterberg-Buchwald ${ }^{2,4}$, Thomas Paul', Joachim Lotz ${ }^{2,4}$, Michael Steinmetz ${ }^{1,4^{*}}$
}

From 18th Annual SCMR Scientific Sessions

Nice, France. 4-7 February 2015

\section{Background}

Arrhythmogenic right ventricular cardiomyopathy (ARVC) is associated with increased risk of sudden cardiac death. It is a progressive disease that can already manifest itself during childhood and adolescence. Since little is known about the early stage in pediatric patients, this study sought to determine the influence of right and left ventricular findings from cardiac magnetic resonance imaging $(\mathrm{CMR})$ in pediatric patients $\leq 18$ years with suspected ARVC in conjunction with positive genetic testing.

\section{Methods}

In a consecutive series between September 2010 and December 2013 (38 months), 79 (14.0 \pm 3.9 years, 46 male) young patients $\leq 18$ underwent contrast-enhanced magnetic resonance imaging (CMR, $1.5 \mathrm{~T}$ Siemens Symphony) and genetic analysis for evaluation of clinically suspected ARVC. CMR parameters were derived from standard SSFP sequences, using comercially available segmentation software (QMass, Medis, Leiden, The Netherlands). CMR parameters were evaluated for predictive values, specificity and senstivity with regard to positive genetic test results.

\section{Results}

12 patients revealed disease defining mutations in either the PKP2 or DSP gene. On CMR, 5 patients showed major criteria due to a combination of moderate to severe RV

${ }^{1}$ Pediatric Cardiology and Intensive Care, University Medical Center Goettingen, Goettingen, Germany

Full list of author information is available at the end of the article dysfunction and dilation as well as regional akinesia. Applying the revised Task Force Criteria (rTFC), 6 patients showed minor abnormalities such as mild RV dilatation, dys-synchronus RV contraction or regional akinesia. Overall 11 out of 12 (92\%) patients with positive genetic characteristics were found to have major or minor abnormalities applying the rTFC. Positive predictive value (PPV) was $100 \%$, negative predictive value (NPV) was $93 \%$, sensitivity was $93 \%$ and specificity was $100 \%$. Mean RV EDVI/BSA was $80 \pm 16 \mathrm{ml}^{2}$ and mean RV EF was $51 \pm 8$ $\%$ in the whole study population. A subgroup analysis revealed a significantly $(\mathrm{p}=0.01)$ decreased mean RV EF of $36 \pm 9 \%$ and an increased RV EDVI/BSA of $101 \pm 10$ $\mathrm{ml} / \mathrm{m}^{2}$ in 11 patients with major or minor abnormalities according to the rTFC.

\section{Conclusions}

This is the first study applying the revised Task Force Criteria (rTFC) for the detection of ARVC to young patient's $\leq 18$. In the current study, CMR revealed 11 out of 12 patient s (major and minor rTFC) with positive findings in genetics with perfect positive predictive value and specificity. In conclusion, CMR is a valuable tool helping to identify ARVC already in pediatric patients, in order to initiate early prevention and treatement.

\footnotetext{
Authors' details

${ }^{1}$ Pediatric Cardiology and Intensive Care, University Medical Center Goettingen, Goettingen, Germany. ${ }^{2}$ Diagnostic and Interventional Radiology, University Medical Center Goettingen, Goettingen, Germany. ${ }^{3}$ Cardiology and Pneumology, University Medical Center, Goettingen, Germany. ${ }^{4}$ German Center for Cardiovascular Research (DZHK), Goettingen, Germany.
} 
Cite this article as: Staab et al: Cardiac magnetic resonance imaging in pediatric patients $\leq 18$ years with suspected arrhythmogenic right

ventricular cardiomyopathy (ARVC): a correlation to genetics. Journal of Cardiovascular Magnetic Resonance 2015 17(Suppl 1):P269.

Submit your next manuscript to BioMed Central and take full advantage of:

- Convenient online submission

- Thorough peer review

- No space constraints or color figure charges

- Immediate publication on acceptance

- Inclusion in PubMed, CAS, Scopus and Google Scholar

- Research which is freely available for redistribution

Submit your manuscript at www.biomedcentral.com/submit 